\title{
Estimation of phenolic conjugation by colonic mucosa
}

\author{
B S RAMAKRISHNA, D GEE, A WEISS, P PANNALL, $\dagger$ I C ROBERTS-THOMSON, \\ W E W ROEDIGER*
}

From the Departments of ${ }^{*}$ Surgery, $\uparrow$ Gastroenterology, and $\ddagger$ Clinical Biochemistry, The Queen Elizabeth
Hospital and University of Adelaide, Woodville, Australia

SUMMARY Conjugation of phenol by the colonic mucosa was assessed in vivo using dialysis tubing containing $1.5 \mathrm{ml}$ of $1 \mathrm{mmol} / \mathrm{l}$ acetaminophen (paracetamol) and $10 \mathrm{mmol} / \mathrm{l}$ butyrate. These were allowed to equilibrate in the rectum for one hour. The glucuronidated and sulphated conjugates of acetaminophen were measured by high pressure liquid chromatography and bicarbonate concentrations by gas analysis. In 21 subjects without colonic disease sulphate conjugation was observed in all cases, with a mean (SE) of $3.86(0.66) \mathrm{nmol} /$ hour, while glucuronide conjugation was found in seven of 21 cases. Mean (SE) bicarbonate output of $42.9(3.9) \mu \mathrm{mol} / \mathrm{hour}(\mathrm{n}=21)$ indicated healthy colonic mucosal metabolism and phenolic sulphation in dialysate and agreed with published sulphation rates obtained with cultured cells of colonic epithelium.

Acetaminophen sulphation suggests that the colonic mucosa has an important role in the conjugation of phenols, and the method reported here would be useful in assessing the detoxification capacity of the colonic mucosa in diseases of the rectal mucosa.

Relatively little attention has been directed towards the capacity of the colonic mucosa to inactivate dietary or bacterial phenols. Self intoxication due to bacterial metabolites from the colon has in the past been regarded as a cause of systemic disease ${ }^{1}$ but a means of measuring conjugation by the colonic mucosa in vivo has not hitherto been available.

Intestinal conjugation of xenobiotics generally occurs as a result of acetylation, glucuronidation, or sulphation. The capacity of the colonic mucosa to sulphate phenols was first reported in $1974^{2}$ and confirmed by studies with mucosal sheets ${ }^{3}$ and isolated epithelial cells ${ }^{4}$ of rat and guinea pig. Most sulphate extracted by colonic epithelial cells ${ }^{5}$ from the blood is converted to active sulphate ${ }^{6}$ which is the universal donor of sulphate ions for sulphation processes and especially for phenolic conjugation. In vitro sulphation in colonic mucosal sheets occurs at a greater rate than glucuronidation for detoxification of phenolic substances derived from the lumen. ${ }^{34}$

To assess inactivation of phenolic substances by the human colon a static method of rectal dialysis ${ }^{7}$ was used to measure sulphation of phenol (paracetamol) by the human colonic mucosa in vivo.

\section{Material and methods}

Twenty one subjects with haemorrhoids but no disease Accepted for publication 19 January 1989 of the colonic mucosa underwent rectal dialysis as previously described. ${ }^{8}$ Dialysis tubing (Visking 8/32) was soaked in distilled water, dry blotted, and filled with dialysis fluid before being placed by proctoscope in the rectum cleared of luminal contents. Each segment of $3 \mathrm{~cm}$ tubing, tied off at each end with " $O$ " silk, contained $1.5 \mathrm{ml}$ distilled water with $10 \mathrm{mmol} / 1$ sodium butyrate, $1 \mathrm{mmol} / \mathrm{l}$ acetaminophen, and $\left[{ }^{14} \mathrm{COOH}\right]$-dextran $\left(4 \times 10^{4}\right.$ counts $\left./ \mathrm{ml}\right)$ as a nondialysable marker for volume correction. The dialysis tubing was left in close mucosal contact for 60 minutes. ${ }^{8}$ Dialysate was discarded when gross faecal pigments, indicating excessive bacterial presence, were observed. Bicarbonate estimation was carried out by microelectrode analysis within three to five minutes of sample collection. Samples stored at $-20^{\circ} \mathrm{C}$, were analysed for paracetamol metabolites by high pressure liquid chromatography in batches of five to six without further treatment or dilution except for filtration through a $0.22 \mu \mathrm{m}$ filter (Millipore). The study was approved by the ethics research committee of the Queen Elizabeth Hospital and written consent was obtained from each subject.

Acetaminophen was obtained from Sigma Chemical $\mathrm{Co}$, and acetaminophen glucuronide standard from Winthrop (Australia) Pty Ltd. Acetaminophen sulphate was donated by $\operatorname{Dr} J$ Miners and synthesised by Dr I Calder of Latrobe University, Melbourne. Sodium n-butyrate was obtained from 

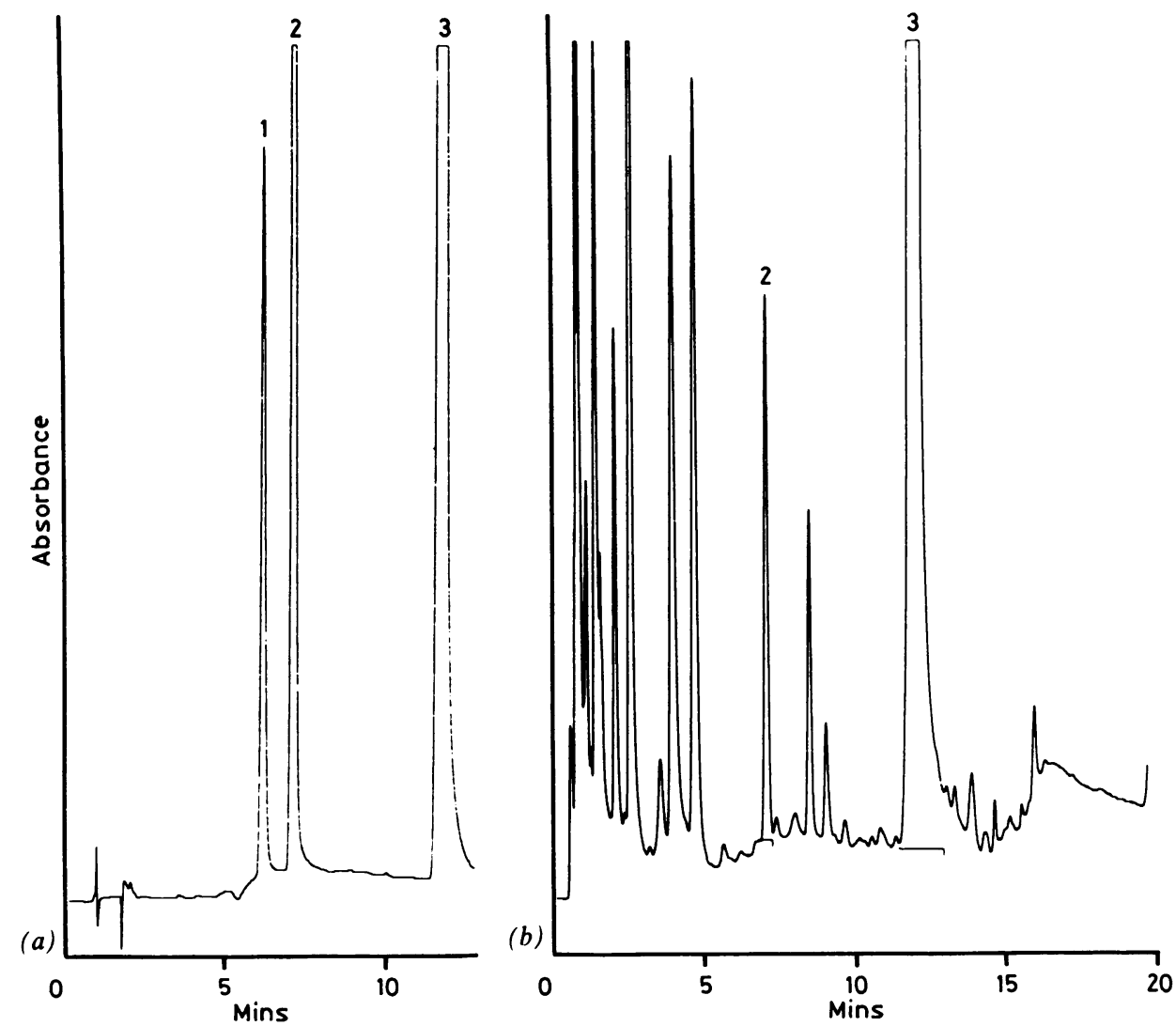

Fig 1 (a) Chromatogram of paracetamol glucuronide (1), paracetamol sulphate (2), and paracetamol (3) standards. (b) Chromatogram of rectal dialysate with a peak of paracetamol sulphate (2) but not of paracetamol glucuronide. The early running peaks might include some other paracetamol metabolites.

BDH (Australia) and $\left[{ }^{14} \mathrm{COOH}\right]$-dextran from New England Nuclear.

The chromatography instrument was a Waters HPLC comprising Model 510 (pump A) and 501 (pump B) pumps with a U6K injector. A guard column, C18-corasil, was used with a Spherisorb $(5 \mu \mathrm{m})$ ODS2 column, $150 \times 46 \mathrm{~mm}$, linked to a ultraviolet detector set at $245 \mathrm{~nm}$. Samples of $20 \mu \mathrm{l}$ were injected manually and peak height data for chromatograms obtained using a Waters 740 data module.

Chromatographic conditions were based, with some differences, on methods previously reported for the measurement of conjugation of paracetamol by the liver. ${ }^{10}$ Technical differences were in the mobile phase, flow rates, and gradient settings were chosen to suit the aqueous samples being analysed. A gradient system was used with the initial mobile phase (A) consisting of $0.1 \mathrm{~mol} / 1 \mathrm{KH}_{2} \mathrm{PO}_{4}$ adjusted to $\mathrm{pH} 3.0$ with o-phosphoric acid. The second mobile phase (B) contained $10 \%$ acetonitrile in $0 \cdot 1 \mathrm{~mol} / 1 \mathrm{KH}_{2} \mathrm{PO}_{4}, \mathrm{pH} 3 \cdot 0$. A linear gradient of $0 \%$ to $50 \%$ was used for 10 minutes, then increased to $100 \%$ B from 10 to 12 minutes, and held at $100 \%$ for a further five minutes. A flow rate of 1.5 $\mathrm{ml} /$ minute was used throughout. The run time was usually 15-18 minutes. Standards were prepared in deionised water: paracetamol $(50-200 \mu \mathrm{mol} / \mathrm{l})$, paracetamol sulphate $(2 \cdot 5-40 \mu \mathrm{mol} / \mathrm{l}), \quad$ and paracetamol glucuronide $(0 \cdot 6-10 \mu \mathrm{mol} / \mathrm{l})$. Peak identifications were made by comparison with authentic standards for each analysis and not verified by means of mass spectrometry.

Bicarbonate output was expressed as $\mu \mathrm{mol} /$ hour (volume after 60 minutes $\times$ bicarbonate concentration). Paracetamol metabolite concentrations in rectal dialysate were calculated by the Waters 740 data module using an external standards method.

\section{Results}

The standard chromatograms of paracetamol and metabolites showed three well separated peaks: the 


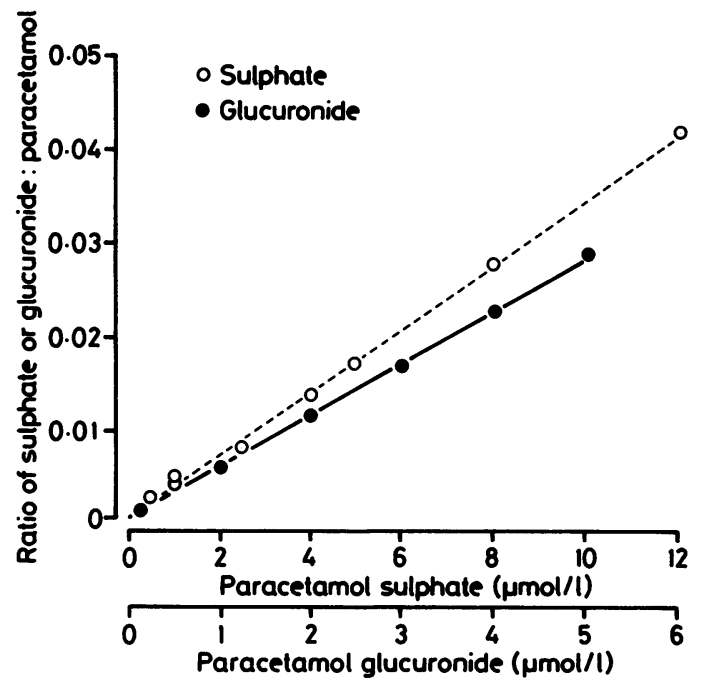

Fig 2 Calibration curves of the ratios of paracetamol sulphate and glucuronide compared against paracetamol as internal standard.

retention time for paracetamol was 12.5 minutes, for paracetamol sulphate 8.9 minutes, and for paracetamol glucuronide 7.6 minutes (fig 1a). In all standard chromatograms the prominent paracetamol peak was used as an internal standard. Calibration graphs were constructed by comparing peak heights of the metabolites to paracetamol: straight lines were obtained for paracetamol sulphate and paracetamol glucuronide (fig 2 ). Reproducibility of graphs was checked with the standards-the coefficient of variation for paracetamol was $7 \cdot 2 \%(n=9)$, paracetamol sulphate $8 \cdot 1 \%(\mathrm{n}=9)$, and paracetamol glucuronide $11 \cdot 1 \%(\mathrm{n}=9)$.

Chromatograms from the dialysate contained numerous early unidentified peaks (fig $1 \mathrm{lb}$ ). Separation of the paracetamol sulphate peak was optimal at $\mathrm{pH}$ 3.0 and could be reliably identified in all chromatograms. Paracetamol glucuronide could only be reliably identified in seven of 21 subjects. Reproducibility of dialysate samples was evaluated: samples from four subjects were assayed in duplicate on the same day giving a coefficient of variation of $6.48 \%$ for paracetamol sulphate and $3.98 \%$ for paracetamol. Paracetamol sulphate was detected in 21 of 21 subjects with a mean (SE) of $3.86(0.66) \mathrm{nmol} /$ hour (range $0.46-10.65$, median value $3.36 \mathrm{nmol} /$ hour); glucuronide sulphate was $0.08(0.4) \mathrm{nmol} / \mathrm{hour}$ (median value $0.0 \mathrm{nmol} /$ hour) in seven of 21 cases. Absence of glucuronidation occurred both with a high or low rate of sulphation. The mean value of bicarbonate output was 42.9 (3.9) $\mu \mathrm{mol} / \mathrm{hour}(\mathrm{n}=21$ ) (fig 3). There was no significant correlation between paracetamol sulphate generation and bicarbonate output $(r=0.3)$.

\section{Discussion}

Rectal dialysis has become widely used to assess the absorptive and metabolic activities of the colonic mucosa. Applications of the technique include the absorption of nutrients ${ }^{11}$ or short chain fatty acids, ${ }^{12}$
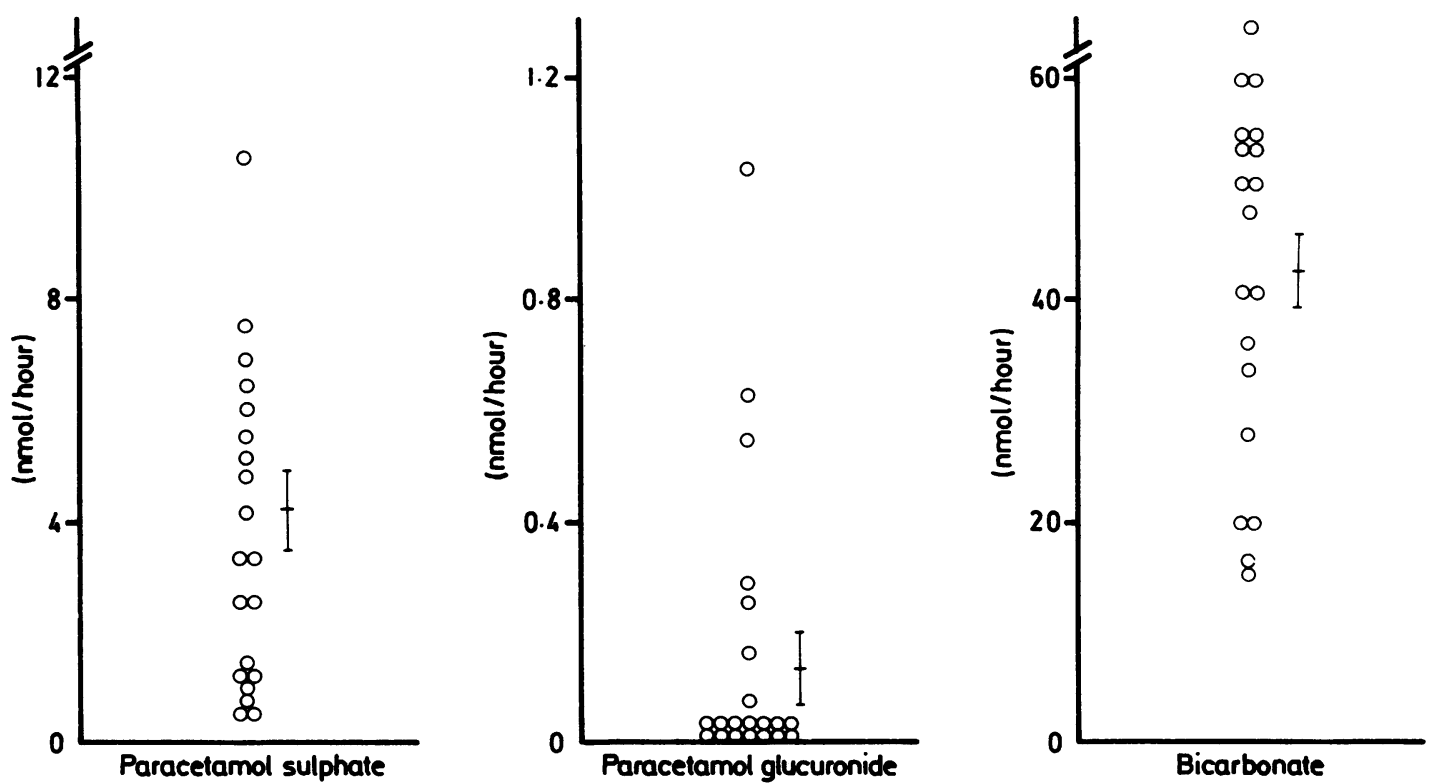

Fig 3 Concentrations of conjugated paracetamol and bicarbonate output in rectal dialysate. Values are mean (SE) of observations in dialysate of the same cases. 
and the production of bicarbonate ions ${ }^{7}$ and prostaglandins ${ }^{13}$ The first demonstration that substances in dialysis bags could influence metabolic reactions in colonic mucosa entailed the use of n-butyrate and the generation of mucosal bicarbonate. ${ }^{7}$ This principle led to the use of paracetamol in dialysis bags in the current study. Bicarbonate output was similar to that in control subjects in a previous study and confirmed the metabolic integrity of the colonic mucosa.

The method of measuring acetaminophen and its conjugates by high pressure liquid chromotography in dialysate is similar to that reported by others ${ }^{910}$ for measuring conjugates of acetaminophen produced by the liver. Unlike concentrations in serum, the dialysis technique leads to occasional peaks which elute close to the glucuronide standard, suggesting the possibility that glucuronidation may be underestimated. The value of glucuronidation in cultured cells of the colon, however, is only $3.8 \%$ of all radioactively labelled phenol compared with $39.8 \%$ for sulphation ${ }^{14}$ and therefore the low values of glucuronidation of acetaminophen observed in this study may be a true reflection of the conjugation capacity by the colonic mucosa in vivo. The ratios of glucuronidation to sulphation of the dialysis technique in vivo is reflected by the value obtained for colonic cell cultures in vitro, ${ }^{14}$ a point which supports the view that the conjugation was carried out by epithelium of the mucosa.

Even though phenols may be efficiently extracted by the small intestine,$^{15}$ dietary phenolic compounds do reach the distal colon, the concentrations of which depend on the composition of ingested food. ${ }^{16}$ Measuring the luminal appearance of the conjugates of these phenols would underestimate the actual rate of conjugation of phenols by the mucosa as some conjugated phenol is absorbed into the blood. ${ }^{17}$ Experiments by Sund and Lauterbach ${ }^{3}$ showed that luminally applied phenol appears in its sulphated form in equal amounts on the luminal as well as vascular side. If this observation applies to the intact mucosa in man, then the amount of sulphation currently measured is only $50 \%$ of the actual rate occurring in the colonic mucosa.

The precise role of sulphates in the colon is unknown. Anaerobic bacteria, which cannot be completely removed from the rectum during dialysis, use sulphate for anaerobic respiration during which sulphate is converted to hydrogen sulphide. ${ }^{18}$ Other sulphation reactions such as that of mucus also occur in the colonic epithelial cells. ${ }^{19}$ Sulphate was recently shown to have a protective function against acid in the mucosa of the upper gastrointestinal tract. ${ }^{20} \mathrm{~A}$ protective function may also be operative in the colonic mucosa through sulphation of xenobiotics which are inactivated before they are absorbed into the blood.

The colonic mucosa seems to have a substantial capacity to detoxify phenolic substances, largely by sulphation. This technique may assist with the study of intestinal disorders such as inflammatory bowel disease, where absorption of phenols or toxins may be involved in a variety of extra-intestinal signs such as liver disease and arthritis.

\section{References}

1 Lane WA. Some remarks on chronic intestinal stasis. Lancet 1918; ii:416.

2 Powell GM, Miller JJ, Olavesen AH, Curtis EG. Liver as major organ of phenol detoxication? Nature 1974;252:234-5.

3 Sund RB, Lauterbach F. Drug metabolism and metabolite transport in the small and large intestine: experiments with l-naphthol and phenolphthalein by luminal and contraluminal administration in the isolated guinea pig mucosa. Acta Pharmacol Toxicol 1986;58:74-83.

4 Schwenk M, Locher M. l-naphthol conjugation in isolated cells from liver, jejunum, ileum, colon and kidney of the guinea pig. Biochem Pharmacol 1985;34:697-701.

5 Lane N, Caro L, Otero-Vilardebo LR, Godman GC. On the site of sulfation in colonic goblet cells. $J$ Cell Biol 1964;21:339-51.

6 Pasternak CA. The synthesis of 3'-phosphoadenosine 5'-phosphosulfate by mouse tissues: sulfate activation in vitro and in vivo. J Biol Chem 1960;235:438-42.

7 Roediger WEW, Lawson MJ, Kwok V, Kerr Grant A, Pannall PR. Colonic bicarbonate output as a test of disease activity in ulcerative colitis. J Clin Pathol 1984;37:704-7.

8 Wrong O, Metcalfe-Gibson A, Morrison RBI, Ng ST, Howard AV. In vivo dialysis of faeces as a method of stool analysis. Clin Sci 1965;28:357-75.

9 Moldeus P. Paracetamol metabolism and toxicity in isolated hepatocytes from rat and mouse. Biochem Pharmacol 1978;27: 2859-63.

10 Griffeth LK, Rosen GM, Rauckman EJ. Effects of model traumatic injury on hepatic drug metabolism in the rat. V. Sulfation and acetylation. Drug Metabolism and Disposition 1985;13:398-405.

11 Griffiths DM, Williamson DH, Gough MH. The nutrient enemaback to Billroth. J Pediatr Surg 1986;21:208-10.

$12 \mathrm{McNeil}$ NI, Cummings JH, James WPT. Short-chain fatty acid absorption by the human large intestine. Gut 1978;19:819-22.

13 Rampton DS, Sladen GE, Youlten LJF. Rectal mucosal prostaglandin $E_{2}$ release and its relation to disease activity, electrical potential difference and treatment in ulcerative colitis. Gut 1980; 21:591-6.

14 Cohen GM, Grafstrom RC, Gibby EM, Smith L, Autrup H, Harris CC. Metabolism of benzo (a) pyrene and 1 naphthol in cultured human tumorous and nontumorous colon. Cancer Res 1983;43:1312-5.

15 Hoensch HP, Schwenk M. Intestinal absorption and metabolism of xenobiotics in humans. In: Schiller CM, ed. Intestinal toxicology. New York: Raven Press, 1984:169-92.

16 Adams RF, Evans AJ, Oakenfull DG, Sidhu GS. The effect of dietary fibre on phenol production in the rat caecum. Proc Aust Nutr Soc 1987;12:100.

17 Hackford AW, Mayhew JW, Goldin BR. An isolated perfused model for the study of colonic metabolism and transport. J Surg Res 1988;44:14-25.

18 Postgate JR. The sulphate-reducing bacteria. 2nd ed. London: Cambridge University Press, 1984.

19 Pasternak CA, Kent PW. Biosynthesis of intestinal mucins 2. Incorporation of $\left[{ }^{35} \mathrm{~S}\right]$ sulphate by guinea-pig colon in vitro. Biochem J 1958;68:452-7.

20 Tobey NA, Orlando RC, Schreiner VJ, Powell DW. Cytoprotective effect of sulfate ions in acid-exposed rabbit esophagus. Am J Physiol 1986;251:G866-9.

Requests for reprints to: Mr W E W Roediger, Department of Surgery, The Queen Elizabeth Hospital, Woodville SA 5011, Australia. 